\title{
Detection of Chromosomal Segments Introgressed from Wild Species of Carrot into Cultivars: Quantitative Trait Loci Mapping for Morphological Features in Backcross Inbred Lines
}

\author{
Chenggang Ou ${ }^{1,+} \oplus$, Tingting Sun ${ }^{1,+}$, Xing Liu ${ }^{1}$, Chengjiang $\mathrm{Li}^{2}, \operatorname{Min~Li}^{1}{ }^{1}$, Xuewei Wang ${ }^{1}$, Huaifu Ren ${ }^{2}$, \\ Zhiwei Zhao ${ }^{1}$ and Feiyun Zhuang ${ }^{1, *(1)}$
}

check for updates

Citation: Ou, C.; Sun, T.; Liu, X.; Li, C.; Li, M.; Wang, X.; Ren, H.; Zhao, Z.; Zhuang, F. Detection of

Chromosomal Segments Introgressed from Wild Species of Carrot into Cultivars: Quantitative Trait Loci Mapping for Morphological Features in Backcross Inbred Lines. Plants 2022, 11, 391. https://doi.org/ 10.3390/plants11030391

Academic Editors: Gianni Barcaccia, Alessandro Vannozzi and

Fabio Palumbo

Received: 4 January 2022

Accepted: 28 January 2022

Published: 30 January 2022

Publisher's Note: MDPI stays neutral with regard to jurisdictional claims in published maps and institutional affiliations.

Copyright: (C) 2022 by the authors. Licensee MDPI, Basel, Switzerland. This article is an open access article distributed under the terms and conditions of the Creative Commons Attribution (CC BY) license (https:// creativecommons.org/licenses/by/ $4.0 /)$.
1 Key Laboratory of Horticultural Crop Biology and Germplasm Innovation, Ministry of Agriculture, Institute of Vegetables and Flowers, Chinese Academy of Agricultural Science, Beijing 100081, China; ouchenggang@caas.cn (C.O.); yixuansmile@163.com (T.S.); liuxing02@caas.cn (X.L.); li1504850091@163.com (M.L.); 18730285257@163.com (X.W.); zhaozhiwei@caas.cn (Z.Z.)

2 Suzhou Academy of Agricultural Science, Suzhou 234000, China; sznks@163.com (C.L.); renhfsz@163.com (H.R.)

* Correspondence: zhuangfeiyun@caas.cn

+ These authors contributed equally to this work.

\begin{abstract}
Cultivated carrot is thought to have been domesticated from a wild species, and various phenotypes developed through human domestication and selection over the past several centuries. Little is known about the genomic contribution of wild species to the phenotypes of present-day cultivars, although several studies have focused on identifying genetic loci that contribute to the morphology of storage roots. A backcross inbred line (BIL) population derived from a cross between the wild species Daucus carota ssp. carota "Songzi" and the orange cultivar "Amsterdam forcing" was developed. The morphological features in the BIL population became more diverse after several generations of selfing $\mathrm{BC}_{2} \mathrm{~F}_{1}$ plants. Only few lines retained features of wild parent. Genomic resequencing of the two parental lines and the BILs resulted in 3,223,651 single nucleotide polymorphisms (SNPs), and 13,445 bin markers were generated using a sliding window approach. We constructed a genetic map with 2027 bins containing 154,776 SNPs; the total genetic distance was $1436.43 \mathrm{~cm}$ and the average interval between the bins was $0.71 \mathrm{~cm}$. Five stable QTLs related to root length, root shoulder width, dry material content of root, and ratio of root shoulder width to root middle width were consistently detected on chromosome 2 in both years and explained 23.4-66.9\% of the phenotypic variance. The effects of introgressed genomic segments from the wild species on the storage root are reported and will enable the identification of functional genes that control root morphological traits in carrot.
\end{abstract}

Keywords: carrot; morphological traits; introgression; backcross inbred lines; quantitative trait locus (QTL)

\section{Introduction}

Wild carrot (Daucus carota L. ssp. carota) is a widespread weedy species that is distributed in Europe, Southwest and Central Asia, North Africa, North and South America [1,2], and found from Afghanistan to the Mediterranean area [3]. Approximately 5600 carrot and Daucus species accessions have been collected and preserved worldwide [1]. The purple and yellow carrot cultivars (D. carota L. ssp. sativus) can be regarded as early ancestral types from approximately 1100 years ago [4,5], the red or purple-red cultivars are recorded from about 440 years ago [6], and orange cultivars are not reliably reported until the sixteenth century in Europe [7]. Over the last few centuries, the carrot has become one of the most important and nutritional Apiaceae crops. Various cultivars with orange roots have been developed to meet consumer demands; examples are "Nantes", 
"Kuroda", "Imperator", and "Amsterdam forcing" [1]. Recent molecular evidence suggested that wild species have made significant contributions to carrot evolution and domestication [4-6,8-10]. Gene flow between cultivated and wild carrot has resulted in domesticated carrot sharing many of the same alleles as wild carrot [11]. An open question is to what extent the genome segments originating from wild carrot species affect phenotypes in the cultivars. At present, little is known about the roles that wild species have played in the domestication of carrot.

Marker-assisted selection (MAS) has been proven to be an effective tool for crop breeding and genetic studies of target traits in plants [12,13], but the efficiency is highly dependent on the precise quantitative trait loci (QTLs) or markers [14,15]. A high-resolution genetic map can greatly improve the efficiency of QTL detection, discovery of potential functional genes, and assembly of genome sequence. The density of genetic maps can be improved by developing polymorphic molecular markers that are distributed throughout the genome using high-throughput sequencing technology [16]. Sequencing with low coverage is one of the most economical and effective methods for rapid development of many genome-wide single nucleotide polymorphism (SNP) markers [17,18]. A sliding window strategy, which combines multiple SNPs with the same genotype into a bin marker with polymorphism, has been successfully applied to the construction of genetic maps and to QTL analysis [15-17,19]. The carrot genome sequence has been published [5]. Consequently, several high-throughput genotyping-based platforms were used to develop sequence-based SNP markers to construct high-density linkage maps and discover key genes or QTLs related to storage root traits such as carotenoid accumulation, anthocyanin content, root development, and biomass [5,20-24].

Growth of the carrot storage root is controlled by a sophisticated regulatory network which consists of multiple endogenous and external factors. The heritability of root width and length is controlled by additive variance and the interaction between additive variance and environmental variance [25]. The root length increases most at low temperatures, and the lower part of the root thickens slowly at moderate temperatures [26]. Increasing plant density is accompanied by a decrease in root length and the development of a cylindrical shape in young roots [27]. Furthermore, root growth and development can be regulated by endogenous hormones [28]. For example, auxins can alter root development in a tissuespecific and stage-dependent manner [29]. Gibberellin not only inhibited root enlargement and stimulated shoot growth but was also found to enhance lignification in the secondary xylem [30,31]. Recently, five QTLs were detected that relate to root thickening, and a candidate gene, DcAHLc1, was proposed to regulate root development [22]. Numerous QTLs have been identified in the carrot genome that are involved in regulating shoot height, biomass, and petiole number; for example, root length and biomass QTLs were identified on chromosomes 1, 2, and 7 [23]. A $180 \mathrm{~kb}$ region on chromosome 1 was found to be related to root shoulder diameter; this region explained $10 \%$ of the phenotypic variance and was thought to control secondary growth of the root [32].

Backcross inbred lines (BILs) can assess the phenotypes of plants with genetically identical genes or loci and improve the accuracy of phenotyping without increasing the effort of genotyping. More importantly, BILs can be used to analyze the interactions between genetic and environmental factors [33]. In this study, a BIL population derived from crossing D. carota ssp. carota "Songzi" (Ws) with an orange cultivar D. carota ssp. sativus "Amsterdam forcing" (Af) was used to study the genetics of carrot morphological traits. The root features of the $\mathrm{BC}_{1} \mathrm{~F}_{1}$ and BIL plants will allow us to evaluate the effect of wild species on the evolution and domestication of carrot. The morphology of the BIL population plants was investigated and compared for two years, and stable QTLs related to them were detected with a high density bin map. This study will provide new insights into our understanding of the influence of genetic and environmental interactions on morphological traits and contribute to the identification of putative functional genes. Furthermore, it will be possible to illustrate the genetic mechanisms of root shape and size of carrot in future. 


\section{Materials and Methods}

\subsection{Plant Materials and Morphological Evaluation}

D. carota ssp. carota "Songzi" (Ws) collected from Hubei province does show a biennial growth habit in nature [2], but we found that it is sensitive to bolting and flowering under long-day conditions even without low temperatures, and it can complete its reproductive cycle from seed to seed in 4-6 months as an annual [34,35]. D. carota ssp. sativus "Amsterdam forcing" (Af) is an orange-rooted European cultivar (Western type) [1]. An $F_{1}$ hybrid was produced by crossing the wild species Ws with the cultivar Af. The $\mathrm{BC}_{1} \mathrm{~F}_{1}$ generations were generated by backcrossing the $\mathrm{F}_{1}$ to the Af parent using artificial emasculation, and only 65 of 80 offspring were left to generate $\mathrm{BC}_{2} \mathrm{~F}_{1}$. Four or five individuals from each $\mathrm{BC}_{2} \mathrm{~F}_{1}$ were randomly screened as the candidates ( $302 \mathrm{BC}_{2} \mathrm{~F}_{1}$ plants) and were then self-pollinated for six generations through single-seed descent (SSD) to develop a set of $223 \mathrm{BC}_{2} \mathrm{~S}_{6}$ plants that together comprised the backcross inbred line (BIL) population. Seeds from 110 BILs were sown in the field with a spacing of $5 \times 15 \mathrm{~cm}$ at the Changping station of the Chinese Academy of Agricultural Science in late July, and the plant morphology was examined in mid-November in 2014 and 2015.

Root color, root length (RL), and root shoulder diameter (the maximum diameter of the root shoulder, RSD) of the $\mathrm{BC}_{1} \mathrm{~F}_{1}$ plants were investigated. Nine measured traits and seven indexes were used to describe the morphology of the BIL population at the vegetative stage [3]. The maximum leaf length (MLL) and leaf weight (LW) were measured to discover the genetic loci that contribute to foliage biomass. RL, RSD, root middle diameter (RMD), root tip diameter (diameter of root tip above the $1 \mathrm{~cm}$ position, RTD), root weight (RW), plant weight (weight of the leaves and root, PW), and dry matter content of the root (DMC) were measured to analyze root biomass and the inheritance of these characters. Seven indexes, LW / RW (iLR), RSD/RMD (iSM), RSD/RTD (iST), RMD/RTD (iMT), RSD/RL (iSL), RMD/RL (iML), and RTD/RL (iTL), were calculated to analyze root shape and biomass distribution. All traits were evaluated using the methods described by IPGRI [3]. Five plants of each BIL were randomly sampled to evaluate the forementioned traits in three biological replicates. This investigation was repeated in 2014 and 2015. Analysis of the variance (ANOVA) and the Pearson correlation coefficients among the traits were determined with SPSS software (version 10.0; SPSS, Chicago, IL, USA).

\subsection{Genome Resequencing of the BIL Population}

Leaves were sampled from five plants of each BIL and the two parents, separately, were immediately frozen in liquid nitrogen and stored at $-80^{\circ} \mathrm{C}$. Total genomic DNA was extracted using the cetyltrimethylammonium bromide (CTAB) method with modification as described in Briard [36]. High-throughput genome sequencing of each sample was performed on an Illumina HiSeq 2500 sequencing platform at Biomarker Technologies Co. Ltd. (Beijing, China). The clean reads were filtered by removing adapters, reads containing $>10 \%$ Ns (unknown bases), and reads in which more than $50 \%$ of the bases had a $Q$ score less than 10 . The 100 bp paired-end reads were aligned to the carrot genome using BWA software (http:/ / bio-bwa.sourceforge.net/ (accessed on 1 January 2022)) [5,37]. The sequencing data were available under National Center for Biotechnology Information (NCBI) project PRJNA741874, accession numbers SRR14965956 (Af) and SRR14965957 (Ws). After filtering, the properly and uniquely mapped reads were used to call single nucleotide polymorphisms (SNPs) using the Genome Analysis Toolkit (GATK) with the default parameters [38].

\subsection{SNP Identification and Mapping in the BIL Population}

The SNPs were further filtered using the following criteria: (1) SNPs were homozygous with two parental genotypes, and there were at least 60 BILs with SNPs at a single site; (2) the SNP depth of the two parents was more than fourfold. A modified sliding window approach, as described by Huang et al. [17], was used to identify the genotype and recombination bin. The genotype of each window was called with a window size of 
$50 \mathrm{bp}$ and a step size of $1 \mathrm{bp}$ and determined based on the ratio of SNPs with genotype of two of the parents: when more than 2/3 of the SNPs had one parental genotype, the window was considered homozygous; otherwise, the window was considered as heterozygous. Adjacent $50 \mathrm{~kb}$ intervals without recombination breakpoints in all 110 BILs were combined into one recombination bin; bins were excluded using the chi-square test with a $p$ value less than 0.005 [17]. The genetic map was constructed with JoinMap version 4.0 (https:/ / www.kyazma.nl/index.php/JoinMap/ (accessed on 1 January 2022)) with default parameters and the genetic distances between bins were calculated using the Kosambi mapping function [39]. Linkage groups were oriented and numbered by aligning resequencing data to the carrot genome and corresponded to nine chromosomes [5].

\subsection{QTL Analysis}

The morphological traits and seven indexes were detected with the composite interval mapping (CIM) approach using Windows QTL Cartographer (WinQTLCart) version 2.5 [40]. The parameters were followed for Model 6: forward-backward stepwise regression as the background control, scanning window size $10.0 \mathrm{~cm}$, walk speed $1.0 \mathrm{~cm}$ and the logarithm of the odds (LOD) threshold value determined with 1000 permutations at a significance level of 0.05 , and a $95 \%$ confidence interval in the QTL region [40].

\section{Results}

\subsection{Morphology of the $F_{1}$ Hybrid and the Backcross Progeny Plants}

The root of the wild species (Ws) accession SRR14965957 (D. carota ssp. carota "Songzi") is white, conical in shape, inedible, and lignified with deep lateral root scars and tiny lateral roots, and the plants complete their reproductive cycle as annuals [35]. Cultivar Af has a biennial growth habit, and its root is orange and cylindrical in shape with a small purple/green shoulder area (Figure 1A). Some morphological traits of the $\mathrm{F}_{1}$ hybrid such as leaf number, white root, conical shape, deep lateral root scars, rough skin, and annual growth habit were clearly inherited from the Ws parent [34], but other traits showed obvious heterosis, such as MLL and RL (Figure $1 \mathrm{~A}, \mathrm{D})$. Most of the $\mathrm{BC}_{1} \mathrm{~F}_{1}$ plants showed inheritance of traits from the recurrent Af parent, such as cylindrical roots with smooth skin, but a few of the plants retained traits from Ws such as premature bolting or many lateral roots (Figure $1 \mathrm{~B}$ ). It was noteworthy that the $\mathrm{BC}_{1} \mathrm{~F}_{1}$ plants showed diversity in terms of root color that ranged from white (10 plants), to pale yellow (21), yellow (25), pale orange (14), and orange (10). $\mathrm{RL}$ in the $\mathrm{BC}_{1} \mathrm{~F}_{1}$ plants was $7.6-22.3 \mathrm{~cm}$, and RSD was 1.9-5.2 cm (Figure 1D). After 65 of the $\mathrm{BC}_{1} \mathrm{~F}_{1}$ plants were backcrossed with the Af parent again, $302 \mathrm{BC}_{2} \mathrm{~F}_{1}$ plants were randomly screened to establish the BIL population through single-seed descent (SSD). In the $\mathrm{BC}_{2} \mathrm{~S}_{2}$ generation, the color, shape, and size of the storage roots became more diverse, and root color, in particular, gradually changed from yellow to orange, but there were no plants with purple roots (Figure 1C).

After self-pollination for six generations of SSD, $223 \mathrm{BC}_{2} \mathrm{~S}_{6}$ lines (the BILs) were obtained and they showed a high level of morphological variation in traits such as root color, root skin, RL, RSD, and green shoulder (Figure 1E). Most lines possessed the biennial habit of the Af parent, but four lines (E3609, E4501, E4503, and E5201) maintained the annual habit of the Ws parent. Representative lines from the 110 BILs could be divided into four groups based on RL, root skin, root shape, and green shoulder. In group a, the lines had roots with a conical shape, deep lateral root scars, and rough skin that were inherited from Ws. In group $b$, the lines had much greener shoulders that were different from either of the parents. In group c, the roots were short and conical in shape with sharp tip roots, while in group $d$, the roots had smooth skins, were cylindrical in shape, and had rounded root tips inherited from Af. Moreover, some intermediate root colors were not found as described in a previous report [6]. For example, lines E0909, E0501, and E4608 had pale orange roots with a low $\beta$-carotene content (data not shown; Figure 1E). 

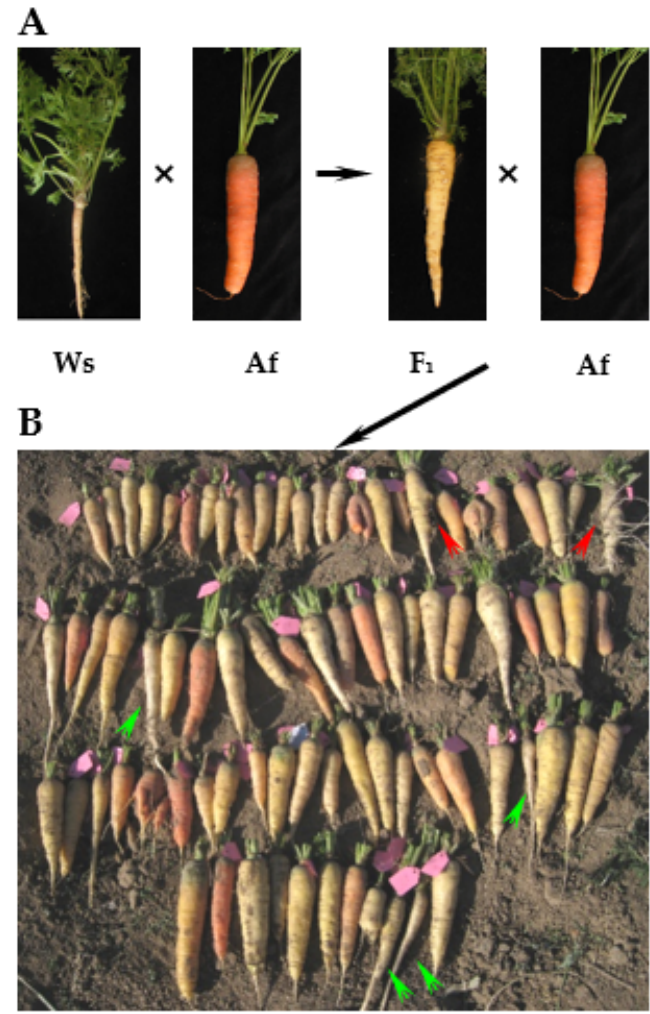

$\mathrm{BC}_{1} \mathrm{~F}_{1}(80) \times \mathrm{Af}$

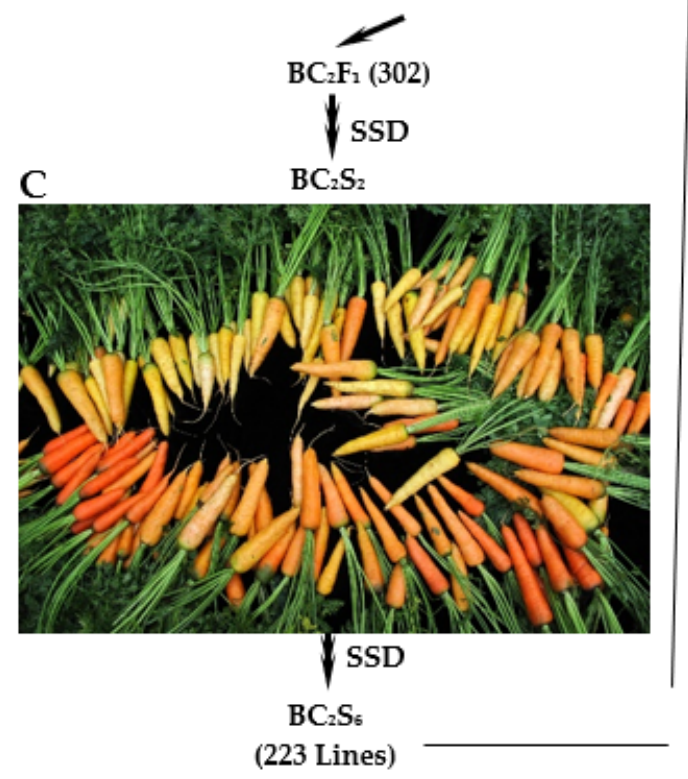

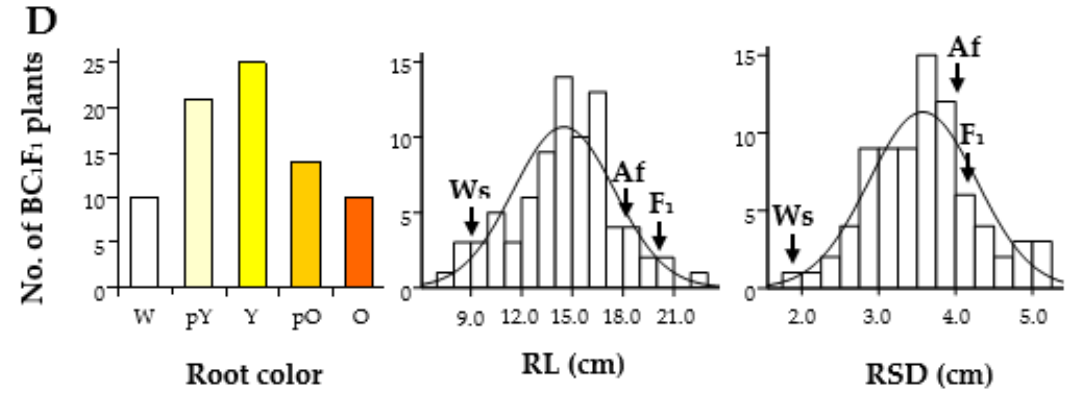

$\mathbf{E}$
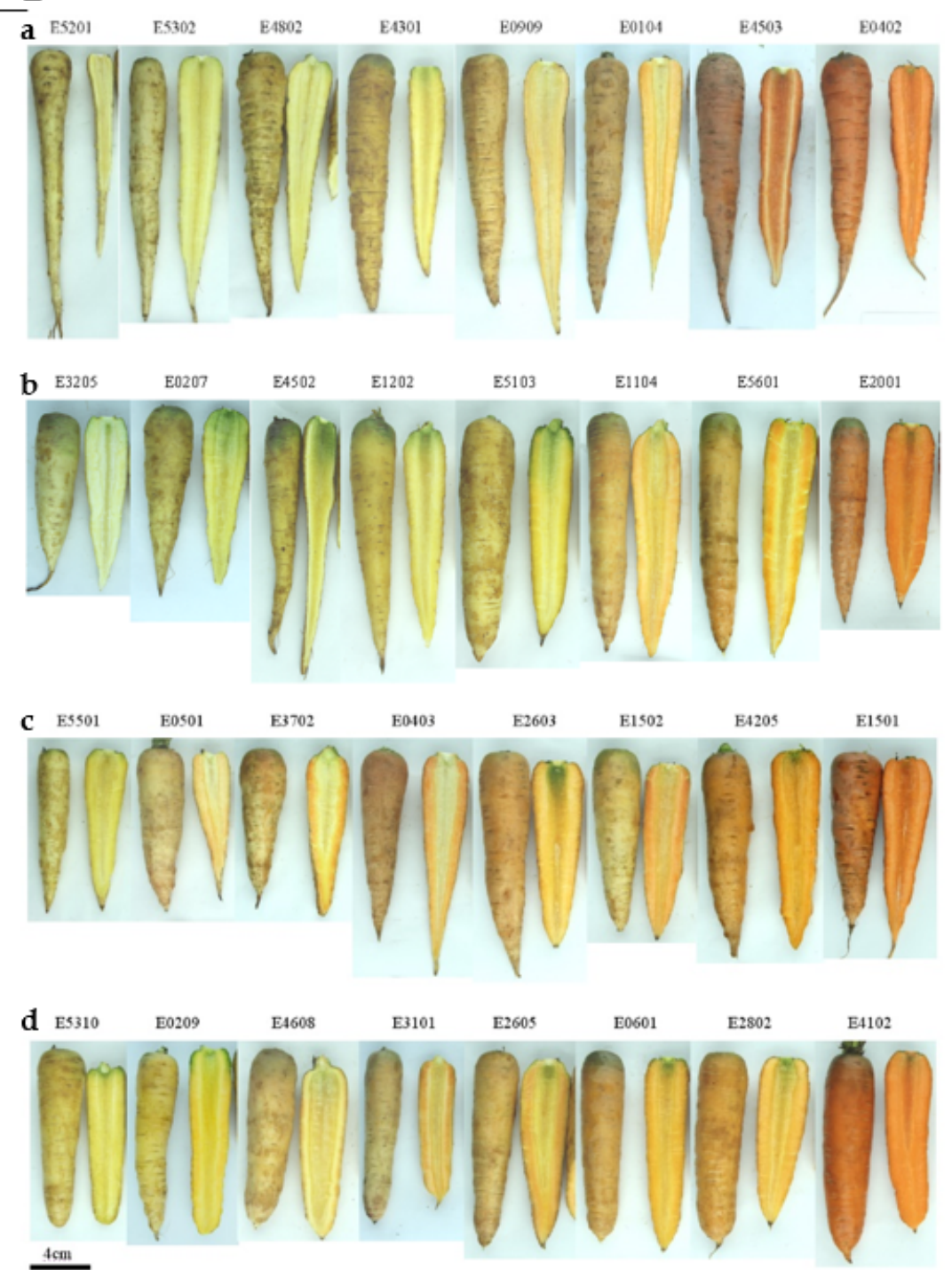

Figure 1. Construction of a population of backcross inbred lines. (A) The morphology of the parents, Ws and Af, and their $F_{1}$. Ws is the wild species with white and conical shape root, deep lateral root scars, and tiny lateral roots. Af is the orange cultivar with cylindrical shape and smooth skin root. The root of $F_{1}$ is white, has a conical shape, and rough skin with deep lateral root scars. (B) The morphology of the $\mathrm{BC}_{1} \mathrm{~F}_{1}$ population with 80 plants. About $65 \mathrm{BC}_{1} \mathrm{~F}_{1}$ plants were left to backcross with the recurrent Af parent. The red arrows show the root with many lateral roots and the green arrows show the premature bolting plants. (C) The morphology of the $\mathrm{BC}_{2} \mathrm{~S}_{2}$ population. SSD, single 
seed descent. (D) Root color, RL, and RSD distribution in the $\mathrm{BC}_{1} \mathrm{~F}_{1}$ population. W: white; pY: pale yellow; Y: yellow; pO: pale orange; O: orange. Black arrows represent the means of Ws, Af, and $\mathrm{F}_{1}$. (E) The morphology of partial $\mathrm{BC}_{2} \mathrm{~S}_{6}$ lines (BILs). Representative lines from 110 BILs could be divided into four groups according to RL, root skin, shape, and green shoulder. (a) The lines were long; the roots were conical in shape with deep lateral scars and rough skin. (b) The lines had a large green shoulder. (c) The lines were short; the roots were conical in shape and had sharp tips. (d) The lines were short; the roots were cylindrical in with smooth skin. Bar is $4 \mathrm{~cm}$.

\subsection{Variation in Morphological Traits in the BIL Population}

Nine measured traits and seven indexes were used to describe the morphological variation present in the BIL population in 2014 and 2015 (Figure 2). The average values for MLL (54.3/54.7 cm), RL (17.2/17.4 cm), DMC (12.4/11.5\%), iSM (1.21/1.21), and iLR $(0.37 / 0.36)$ were similar for the two years. The average values for LW, RSD, RMD, RTD, RW, PW, iML, and iTL in 2014 were significantly lower than in 2015, while the values for iST and iMT were higher in 2014 than in 2015. The range of variation for LW, RSD, RMD, RTD, RW, PW, iST, iMT, and iTL were different in the two years.

The correlation coefficients of the nine measured traits in the BIL population are shown for 2014 and 2015 (Table 1). In 2014 and 2015, LW was positively correlated with $\operatorname{MLL}\left(0.62^{* * *} / 0.46^{* * *}\right)$ and RL $\left(0.26^{* *} / 0.57^{* * *}\right)$, but MLL and RL were not correlated; RL was positively correlated with $\operatorname{RSD}\left(0.22^{*} / 0.51^{* * *}\right), \operatorname{RW}\left(0.46^{* * *} / 0.70^{* * *}\right)$, and PW $\left(0.48^{* * *} / 0.72^{* * *}\right)$; PW showed a positive relationship with RSD $\left(0.83^{* * *} / 0.88^{* * *}\right)$, RMD $\left(0.80^{* * *} / 0.83^{* * *}\right)$, RTD $\left(0.35^{* * *} / 0.63^{* * *}\right)$, and RW $\left(0.96^{* * *} / 0.98^{* * *}\right)$; DMC was negatively correlated with RMD $\left(-0.44^{* *} /-0.30^{* *}\right)$ and RTD $\left(-0.40^{* * *} /-0.37^{* *}\right)$.

Table 1. Correlation coefficients of morphological traits in the BIL population.

\begin{tabular}{|c|c|c|c|c|c|c|c|c|c|}
\hline Traits & MLL & LW & RL & RSD & RMD & RTD & RW & PW & DMC \\
\hline MLL & & $0.46^{* * *}$ & 0.18 & 0.06 & -0.01 & 0.08 & 0.10 & 0.20 * & -0.21 * \\
\hline LW & $0.62^{* * *}$ & & $0.57^{* * *}$ & $0.60^{* * *}$ & $0.49^{* * *}$ & $0.31^{* *}$ & $0.63^{* * *}$ & $0.78^{* * *}$ & -0.07 \\
\hline RL & 0.13 & $0.26^{* *}$ & & $0.51^{* * *}$ & $0.42^{* * *}$ & $0.29 * *$ & $0.70^{* * *}$ & $0.72^{* * *}$ & 0.09 \\
\hline RSD & $0.29^{* *}$ & $0.30^{* *}$ & 0.22 * & & $0.87^{* * *}$ & $0.61^{* * *}$ & $0.85^{* * *}$ & $0.88^{* * *}$ & -0.17 \\
\hline RMD & $0.25^{* *}$ & 0.17 & 0.08 & $0.86^{* * *}$ & & $0.75 * * *$ & $0.85^{* * *}$ & $0.83^{* * *}$ & $-0.30^{* *}$ \\
\hline RTD & $0.21 *$ & -0.04 & $-0.25^{* *}$ & $0.30 * *$ & $0.57^{* * *}$ & & $0.41^{* * *}$ & $0.63^{* * *}$ & $-0.37^{* * *}$ \\
\hline $\mathrm{RW}$ & $0.29^{* *}$ & $0.28^{* *}$ & $0.46^{* * *}$ & $0.88^{* * *}$ & $0.86^{* * *}$ & $0.68^{* * *}$ & & $0.98^{* * *}$ & -0.17 \\
\hline PW & $0.44^{* * *}$ & $0.55^{* * *}$ & $0.48 * * *$ & $0.83^{* * *}$ & $0.80^{* * *}$ & $0.35^{* * *}$ & $0.96^{* * *}$ & & $-0.25^{* *}$ \\
\hline DMC & -0.12 & -0.01 & 0.12 & $-0.36^{* * *}$ & $-0.44^{* * *}$ & $-0.40^{* * *}$ & $-0.29 * *$ & -0.16 & \\
\hline
\end{tabular}

Note: The numbers below the diagonal are correlation coefficients in 2014 and the numbers above the diagonal are correlation coefficients in 2015. ${ }^{*}, * *, * * *$ represent $0.05,0.01$, and 0.001 significance levels, respectively. Light gray, gray, and dark gray boxes show the correlation coefficients at $0.05,0.01$, and 0.001 significance levels, respectively.

\subsection{Genotyping and Construction of the Bin Map in the BIL Population}

Genomic DNA from the two parents was sequenced, yielding $5.6 \mathrm{Gbp}$ of clean bases with a depth of approximately tenfold. For Ws and Af, $95.74 \%$ and $97.03 \%$ of the total reads could be aligned to the carrot reference genome and covered $88.62 \%$ and $93.3 \%$ of the genome, respectively (Supplementary Table S1). Each BIL was sequenced to approximately 1.8-fold depth. For each BIL, 85.91-97.92\% of the reads were aligned to the reference genome with $44.46-72.41 \%$ coverage. After analysis using the GATK software package, a total of 3,223,651 SNPs were identified, and 333,280 homozygous SNPs were polymorphic between Ws and Af. The ratios of heterozygous SNPs of Ws and Af were $50.81 \%$ and $72.17 \%$, respectively. The average ratio of heterozygous SNPs of the BIL population was $18.88 \%$ and were in the range 7.52-34.31\% (Supplementary Table S1). After filtering, a total of 259,246 recombination breakpoints were detected with an average of 33.2 breakpoints per line. In total, 13,445 bins were generated and used to construct the genetic linkage map. The physical lengths of the bins were in the range $20.04 \mathrm{~kb}-4.21 \mathrm{Mb}$ with an average length of $130.88 \mathrm{~kb}$. 

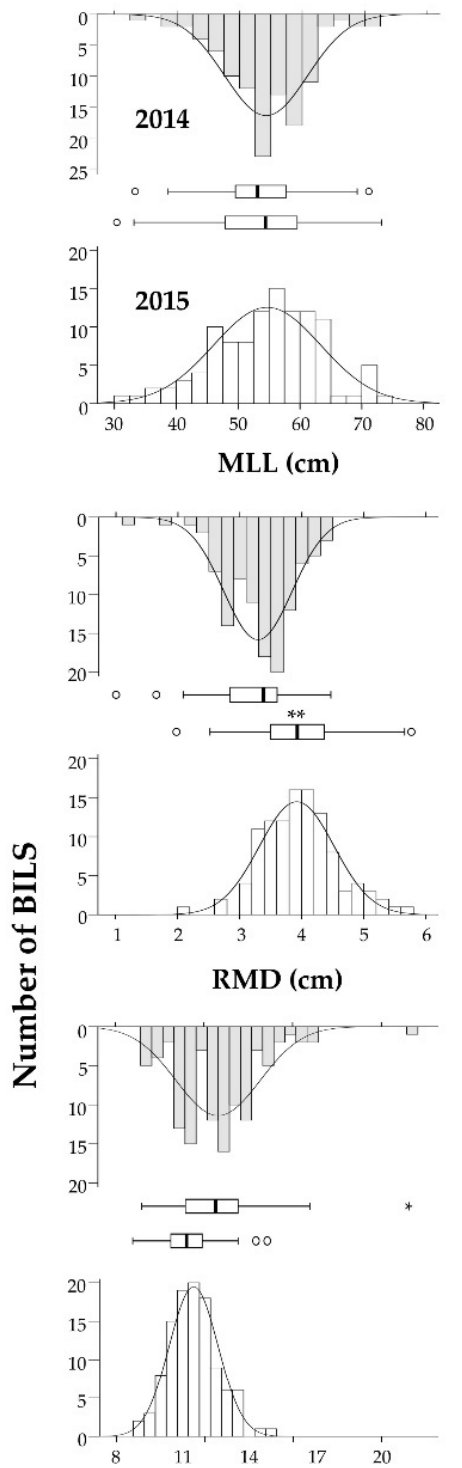

DMC (\%)
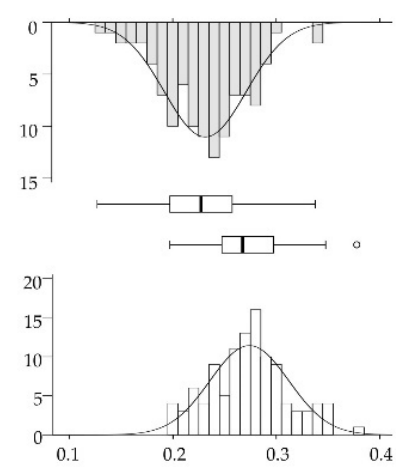

iSL
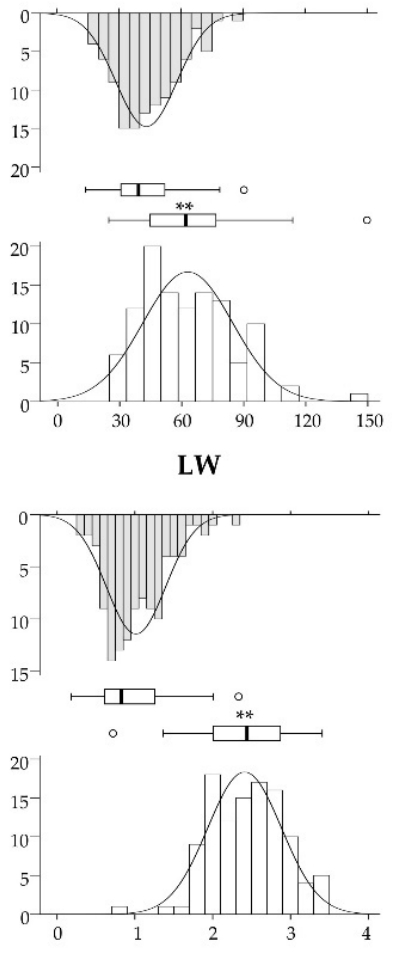

RTD (cm)
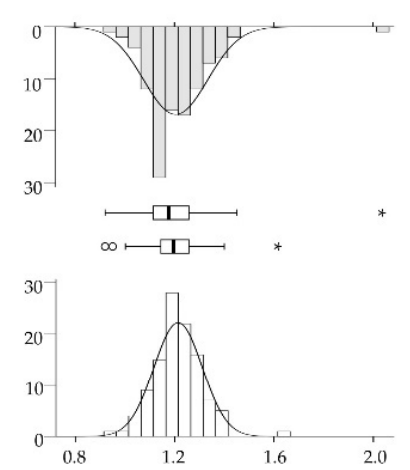

iSM
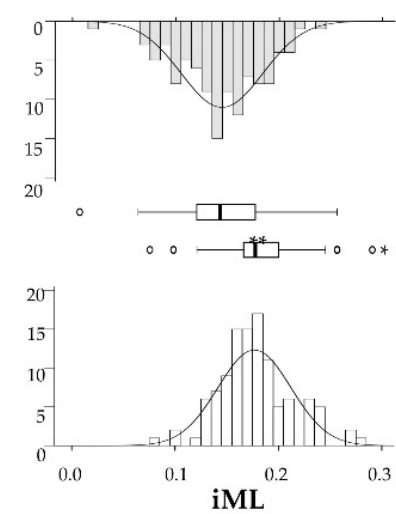
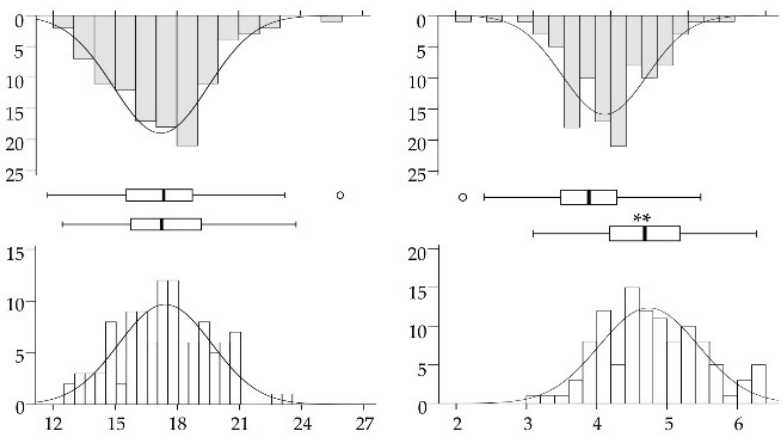

RL (cm)
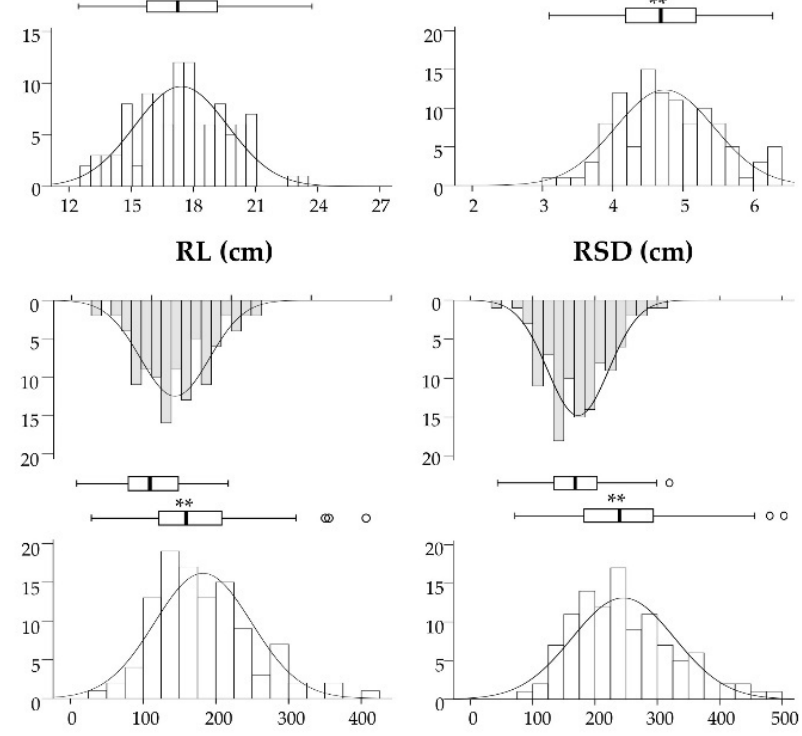

RW (g)
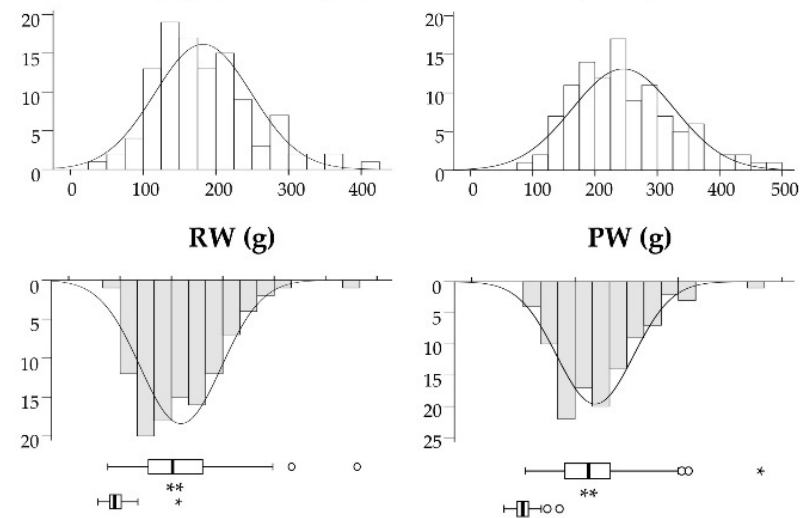

PW (g)
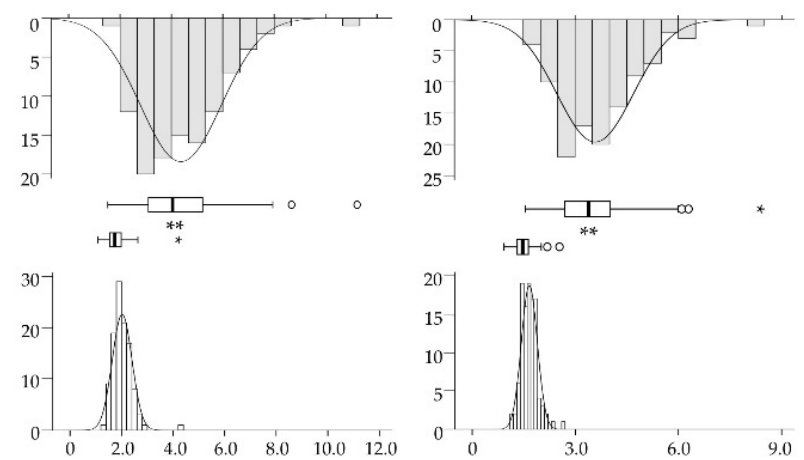

iST
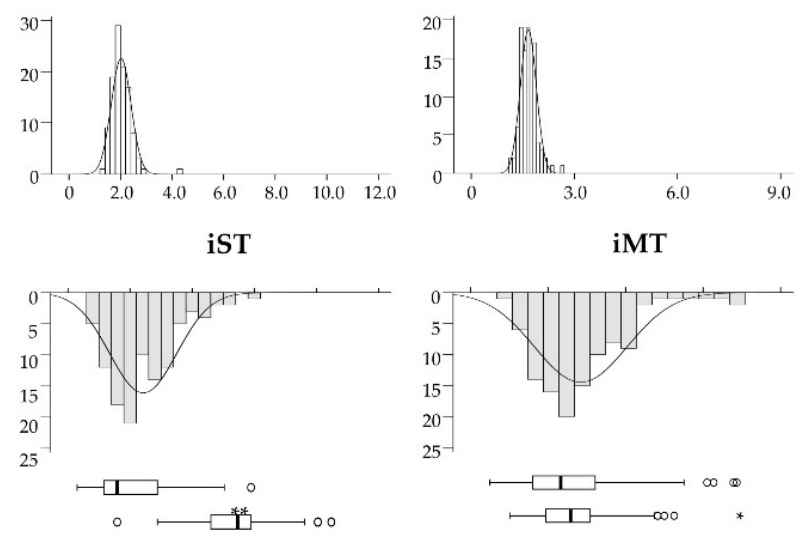

iMT
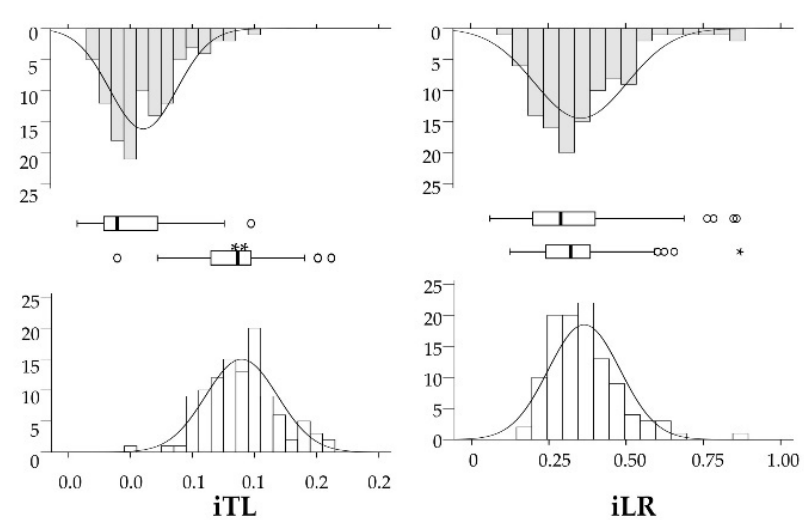

Figure 2. Comparison of the morphological traits in the BIL population. Downward-facing gray histogram shows the distribution of each trait in 2014, and upward-facing white histogram shows the distribution in 2015. The middle boxplots and average values of each trait were analyzed in 2014 and 2015 with ANOVA by SPSS software. * and $\bigcirc$ mean outliers in the boxplot; ${ }^{* *}$ beside white boxes mean the average values of each trait at a significance level of 0.01 . 
A high-density genetic map was constructed by mapping 2027 bins onto the nine carrot chromosomes with an average of 219.6 bins per chromosome (Table 2; Supplementary Table S4). The map consisted of 154,776 SNPs with an average of 76.4 SNPs in each bin. The total recombinational length of the linkage map was $1436.43 \mathrm{~cm}$, with an average interval length of $0.71 \mathrm{~cm}$, which corresponded to a physical distance of $0.33 \mathrm{Mb} / \mathrm{cm}$ over the whole carrot genome [5]. The largest number of bins was on chromosome 4:281 bins containing 22,429 SNPs, with an average distance of $0.60 \mathrm{~cm}$ between adjacent bins covering a genetic length of $167.26 \mathrm{~cm}$. Chromosome 8 had the smallest number of bins (141 containing 5564 SNPs), and it had the largest average genetic distance of $1.18 \mathrm{~cm}$ between bins for a genetic length of $166.27 \mathrm{~cm}$. Large gaps were present on each chromosome, and the largest gap was $16.88 \mathrm{~cm}$ on chromosome 2.

Table 2. Characteristics of the high-density genetic map.

\begin{tabular}{|c|c|c|c|c|c|}
\hline Chr ${ }^{a}$ & Number of SNPs & Number of Bins & Genetic Distance $(\mathrm{cm})$ & $\begin{array}{c}\text { Average Distance between } \\
\text { the Neighbor Bins (cm) }\end{array}$ & Max Gap (cm) \\
\hline 1 & 19,430 & 184 & 160.48 & 0.87 & 13.54 \\
\hline 2 & 27,142 & 249 & 114.70 & 0.46 & 16.88 \\
\hline 3 & 28,062 & 267 & 170.46 & 0.64 & 12.02 \\
\hline 4 & 22,429 & 281 & 167.26 & 0.60 & 5.02 \\
\hline 5 & 7986 & 224 & 202.93 & 0.91 & 7.96 \\
\hline 6 & 12,070 & 194 & 162.37 & 0.84 & 10.60 \\
\hline 7 & 17,491 & 250 & 143.02 & 0.58 & 3.93 \\
\hline 8 & 5564 & 141 & 166.27 & 1.18 & 14.33 \\
\hline 9 & 14,602 & 237 & 148.97 & 0.63 & 8.59 \\
\hline Average & 17,197 & 225 & 159.61 & - & 10.32 \\
\hline Total & 154,776 & 2027 & 1436.43 & 0.71 & - \\
\hline
\end{tabular}

${ }^{\text {a }}$ Chr indicates chromosome.

We found that small segments of the Ws genome were randomly distributed on each chromosome in most cases (Figure 3) and the percentage of homozygous bins from Ws ranged from $3.5 \%$ (chromosome 2) to $9.7 \%$ (chromosome 1 ) with an average of $5.8 \%$ (Supplementary Table S3). For each BIL, 76.4-99.4\% of the homozygous bins were from the Af parent, while those from the Ws parent comprised 0.6-23.6\% (Figure 3, Supplementary Tables S2 and S3). For example, $0.6 \%$ of the genome of E2802, a line with a pale orange root with a cylindrical shape and round tip (Figure 1E(d)), came from Ws and 99.4\% came from Af (Figure 3a); the E5201 line had a small white root and an annual growth habit (Figure 1E(a)), with $23.6 \%$ of the genome coming from Ws and 76.4\% from Af (Figure 3b). However, notably, many genomic segments originating from Ws were clustered at the terminus of chromosome 1 in most of the BILs, and some large segments were also maintained in some BILs. For example, line E1202 has a large Ws genomic segment on chromosome 9 but has a pale orange root with smooth skin (Figure 3c); 52.21\% of chromosome 2 in line E5302 came from the Ws genome (Figure 3d), and the plants have small white storage roots and rough skin (Figure 1E(a)). 
Chr1 $\mathrm{Chr2}$
Chr3

Chr4

Chr5

Chr6

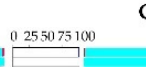

$\mathrm{Chr} 7$

Chr8

Chr9

\section{Average}

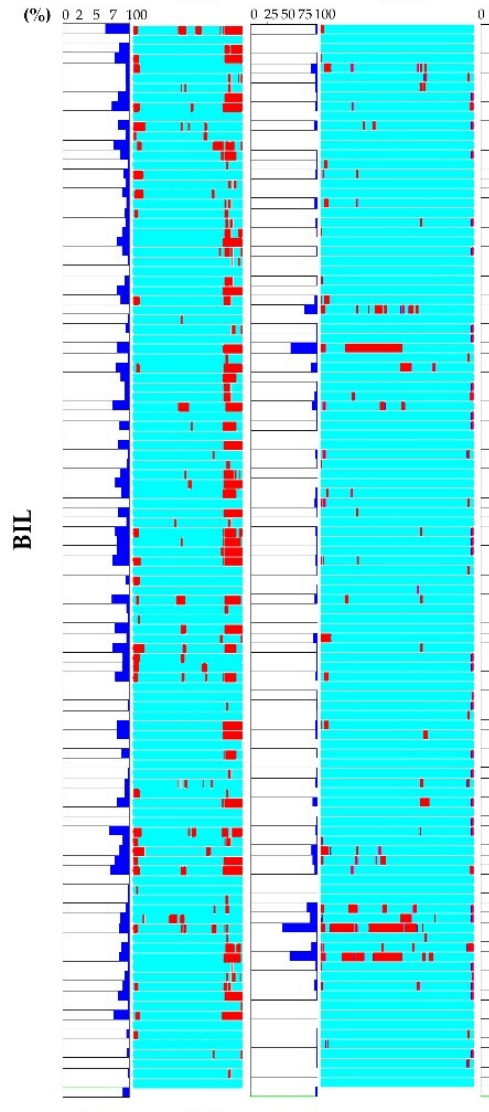

口ㅁ Af
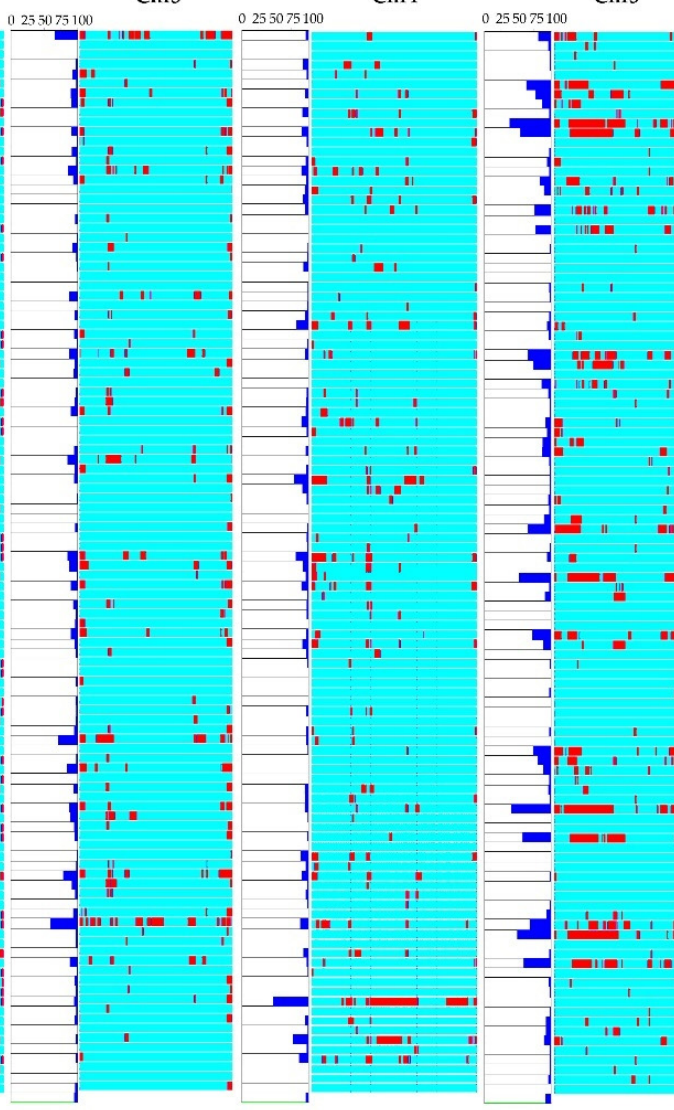

Bin marker

Figure 3. Recombination bin map of the BIL population. Each line represents bin markers in the order of the linkage map. White and blue columns represent the ratio of homozygous bins from the Af and Ws genomes on the chromosome, respectively. Light blue and red columns represent the genetic regions of homozygous bins from the Af and Ws genomes on the chromosome, respectively. (a) The E2802 line had a pale orange root, cylindrical shape, and round tip, with $0.6 \%$ and $99.4 \%$ of the genome coming from Ws and Af, respectively. (b) The E5201 line had a small white root and annual growth habit, with $23.6 \%$ and $76.4 \%$ of the genome from Ws and of Af, respectively. (c) The E1202 line had a large genome fragment from Ws on chromosome 9 with pale orange root and smooth skin. (d) The E5302 line had $52.21 \%$ of the genome coming from Ws on chromosome 2 and presented small white roots and rough skin. The black arrowhead indicating green boxes shows average relative ratios of the Af (white) and Ws (blue) genome on each chromosome. 


\subsection{QTL Analysis of BIL Morphological Traits}

QTLs for the nine morphological traits and seven indexes were detected in the bin map with WinQTLCart using the CIM method [40]. There were 23 and 25 QTLs identified in 2014 and 2015, respectively, and only five QTLs were found to be stable in both years (Table 3 and Figure 4). Five, 16, 4, 2, 3, 2, 3, 2, and 1 QTLs were located on chromosomes 1 to 9 , respectively, and explained $10.1-66.9 \%$ of the phenotypic variation (Table 3). One QTL was detected for MLL (maximum leaf length), MLL2-1, in 2014 and two QTLs, MLL1-1 and MLL5-1, were detected in 2015, which explained 25.7, 13.2, and 13.9\% of the phenotypic variation, respectively. Both MLL2-1 and MLL1-1 had positive additive effects. Three QTLs, LW1-1, LW1-2, and LW9-1, were detected for LW (leaf weight) in 2014 and two QTLs, LW2-1 and LW2-2, were detected in 2015; these five QTLs explained 12.7, 17.3, 15.2, 13.1, and $16.6 \%$ of the phenotypic variation, respectively. LW1-2 had a positive additive effect, while the other four QTLs had negative additive effects. For RL (root length), RL2-1 was stable in that it was identified in both years and explained $33.7 \%$ and $30.5 \%$ of the phenotypic variation in 2014 and 2015, respectively, and RL2-2 explained that $40.4 \%$ of the phenotypic variation was identified in 2015. Both $R L 2-1$ and $R L 2-2$ had positive additive effects. For RSD (root shoulder diameter), RSD2-1 was detected in 2014 and explained 39.1\% of the phenotypic variation, while another QTL, RSD2-2, was stably detected in both years and explained $39.1 \%$ and $24.6 \%$ of the phenotypic variation, respectively. For RMD (root middle diameter), the QTLs RMD3-1 and RMD2-1 were identified in 2014 and 2015, respectively, and explained $38.9 \%$ and $29.5 \%$ of the phenotypic variation. For RTD (root tip diameter), only one QTL, RTD2-1, was identified in 2014, and explained $12.6 \%$ of the phenotypic variation. For RW (root weight), two QTLs were identified in each year that were located on four chromosomes. RW1-1 and RW5-1 had positive additive effects and explained $10.5 \%$ and $13.2 \%$ of the phenotypic variation, respectively, while $R W 7-1$ and $R W 8-1$ had negative additive effects and explained $11.4 \%$ and $15.9 \%$ of the phenotypic variation in 2014 and 2015, respectively. Three QTLs, PW1-1, PW2-1, and PW4-1, were identified for PW (plant weight) in 2014 and explained 13.2, 18.9, and 15.3\% of the phenotypic variation, respectively, but only one QTL, PW8-1, was identified in 2015, and it explained $14.1 \%$ of the phenotypic variation. PW1-1 and PW2-1 had positive additive effects, but $P W 4-1$ and PW8-1 had negative additive effects. Only one QTL, DMC2-1, was identified for DMC (dry matter content of the root) in both 2014 and 2015 and explained $23.4 \%$ and $37.2 \%$ of the phenotypic variation, respectively. In addition, DMC2-2 and DMC5-1 were identified in 2015 and explained $37.2 \%$ and $32.4 \%$ of the phenotypic variation, respectively.

Table 3. Identified QTLs for BIL morphological traits.

\begin{tabular}{|c|c|c|c|c|c|c|c|c|}
\hline Trait & Year & QTL & Chr & LOD & Position (cm) & QTL Region (cm) & $\begin{array}{l}\text { Additive } \\
\text { Effect }\end{array}$ & $\begin{array}{c}\text { Phenotypic } \\
\text { Variance (\%) }\end{array}$ \\
\hline \multirow[t]{3}{*}{ MLL } & 2014 & MLL2-1 & 2 & 13.9 & 44.9 & $44.4-45.0$ & 23.1 & 25.7 \\
\hline & 2015 & MLL1-1 & 1 & 5.2 & 22.8 & $21.8-23.6$ & 11.8 & 13.2 \\
\hline & 2015 & MLL5-1 & 5 & 5.5 & 37.3 & $35.0-38.3$ & 4.4 & 13.9 \\
\hline \multirow[t]{5}{*}{ LW } & 2014 & LW1-1 & 1 & 7.0 & 0.5 & $0.0-1.6$ & -7.2 & 12.7 \\
\hline & 2014 & LW1-2 & 1 & 6.3 & 37.9 & $36.6-40.7$ & 11.7 & 17.3 \\
\hline & 2014 & LW9-1 & 9 & 5.6 & 39.4 & $37.5-39.9$ & -11.3 & 15.2 \\
\hline & 2015 & $L W 2-1$ & 2 & 4.4 & 54.1 & $53.5-54.6$ & -21.9 & 13.1 \\
\hline & 2015 & $L W 2-2$ & 2 & 5.7 & 64.2 & $63.8-64.8$ & -30.0 & 16.6 \\
\hline \multirow[t]{2}{*}{ RL } & $2014 / 2015$ & $R L 2-1$ & 2 & $13.5 / 10.7$ & 44.9 & $44.4-45.0$ & $8.6 / 8.2$ & $33.7 / 30.5$ \\
\hline & 2015 & $R L 2-2$ & 2 & 11.1 & 35.2 & $34.2-35.6$ & 10.7 & 40.4 \\
\hline \multirow[t]{2}{*}{ RSD } & 2014 & RSD2-1 & 2 & 12.0 & 35.2 & $34.2-35.4$ & 2.3 & 39.1 \\
\hline & $2014 / 2015$ & RSD2-2 & 2 & $16.6 / 9.7$ & 44.9 & $44.4-45.0$ & $2.3 / 2.2$ & $39.1 / 24.6$ \\
\hline \multirow[t]{2}{*}{ RMD } & 2014 & RMD3-1 & 3 & 15.0 & 96.3 & $95.8-96.7$ & 1.5 & 38.9 \\
\hline & 2015 & RMD2-1 & 2 & 11.8 & 44.9 & $44.4-45.0$ & 2.0 & 29.5 \\
\hline RTD & 2014 & RTD2-1 & 2 & 4.5 & 4.9 & $1.6-6.8$ & 0.2 & 12.6 \\
\hline
\end{tabular}


Table 3. Cont.

\begin{tabular}{|c|c|c|c|c|c|c|c|c|}
\hline Trait & Year & QTL & Chr & LOD & Position (cm) & QTL Region (cm) & $\begin{array}{c}\text { Additive } \\
\text { Effect }\end{array}$ & $\begin{array}{l}\text { Phenotypic } \\
\text { Variance (\%) }\end{array}$ \\
\hline \multirow[t]{4}{*}{ RW } & 2014 & $R W 1-1$ & 1 & 4.1 & 35.5 & 34.4-38.1 & 27.3 & 10.5 \\
\hline & 2014 & RW5-1 & 5 & 4.5 & 158.8 & $157.7-159.5$ & 49.3 & 13.2 \\
\hline & 2015 & RW7-1 & 7 & 4.4 & 124.9 & $124.0-125.5$ & -44.5 & 11.4 \\
\hline & 2015 & RW8-1 & 8 & 5.4 & 155.9 & $155.2-156.6$ & -104.7 & 15.9 \\
\hline \multirow[t]{4}{*}{ PW } & 2014 & PW1-1 & 1 & 4.9 & 36.5 & $35.1-38.0$ & 33.6 & 13.2 \\
\hline & 2014 & PW2-1 & 2 & 7.1 & 44.9 & $44.4-45.0$ & 123.2 & 18.9 \\
\hline & 2014 & PW4-1 & 4 & 5.9 & 160.1 & 158.3-161.5 & -34.2 & 15.3 \\
\hline & 2015 & PW8-1 & 8 & 5.2 & 154.9 & $154.4-156.1$ & -89.2 & 14.1 \\
\hline \multirow[t]{3}{*}{ DMC } & $2014 / 2015$ & DMC2-1 & 2 & $12.3 / 20.9$ & 44.9 & $44.4-45.0$ & $0.1 / 0.1$ & $23.4 / 37.2$ \\
\hline & 2015 & $D M C 2-2$ & 2 & 16.1 & 35.2 & $34.2-35.5$ & 0.1 & 37.2 \\
\hline & 2015 & DMC5-1 & 5 & 18.9 & 159.7 & $158.8-159.9$ & -0.1 & 32.4 \\
\hline \multirow[t]{3}{*}{ iSM } & $2014 / 2015$ & iSM2-1 & 2 & $25.1 / 22.3$ & 35.2 & $34.2-35.4$ & $1.1 / 0.6$ & $66.9 / 55.7$ \\
\hline & $2014 / 2015$ & iSM2-2 & 2 & $29.7 / 27.0$ & 44.9 & $44.4-45.0$ & $1.1 / 0.6$ & $66.9 / 55.7$ \\
\hline & 2014 & iSM3-1 & 3 & 15.5 & 94.9 & $94.4-94.9$ & -0.5 & 24.9 \\
\hline \multirow[t]{2}{*}{ iST } & 2014 & iST7-1 & 7 & 11.2 & 84.5 & $84.0-84.9$ & -3.9 & 30.9 \\
\hline & 2015 & iST5-1 & 5 & 12.8 & 159.7 & $158.8-159.9$ & -1.2 & 27.4 \\
\hline \multirow[t]{3}{*}{ iMT } & 2014 & iMT7-1 & 7 & 11.2 & 84.5 & 84.0-84.9 & -2.8 & 31.9 \\
\hline & 2015 & iMT2-1 & 2 & 11.0 & 35.2 & $34.2-35.4$ & 0.9 & 36.3 \\
\hline & 2015 & iMT2-2 & 2 & 15.7 & 44.9 & $44.4-45.0$ & 0.9 & 36.3 \\
\hline \multirow[t]{2}{*}{ iSL } & 2014 & iSL3-1 & 3 & 11.9 & 96.3 & $95.8-97$ & 0.1 & 30.1 \\
\hline & 2015 & iSL2-1 & 2 & 12.1 & 44.9 & $44.4-45.1$ & 0.1 & 31.2 \\
\hline iML & 2014 & iML3-1 & 3 & 6.9 & 96.3 & $95.8-97.5$ & 0.1 & 16.5 \\
\hline \multirow[t]{3}{*}{ iTL } & 2015 & iTL2-1 & 2 & 8.2 & 37.9 & $36.7-39.0$ & 0.0 & 27.6 \\
\hline & 2015 & iTL2-2 & 2 & 7.3 & 45.8 & $45.4-46.4$ & 0.1 & 22.8 \\
\hline & 2015 & iTL2-3 & 2 & 5.0 & 76.1 & $74.7-79.0$ & -0.0 & 12.3 \\
\hline \multirow[t]{3}{*}{ iLR } & 2014 & iLR3-1 & 3 & 5.7 & 96.7 & 96.3-100.1 & 0.2 & 15.7 \\
\hline & 2015 & iLR6-1 & 6 & 6.3 & 25.1 & $24.1-26.9$ & 0.1 & 16.0 \\
\hline & 2015 & iLR6-2 & 6 & 6.2 & 87.1 & $85.9-89.3$ & -0.2 & 18.7 \\
\hline
\end{tabular}

Three QTLs were identified for iSM (index of RSD/RMD) in 2014. iSM2-1, iSM2-2, and iSM3-1 explained $66.9,66.9$, and $24.9 \%$ of the phenotypic variation, respectively. iSM2-1 and iSM2-2 had positive additive effects, but iSM3-1 had a negative additive effect. Notably, iSM2-1 and iSM2-2 were stably detected in 2015 and explained $55.7 \%$ and $55.7 \%$ of the phenotypic variation, respectively. Two QTLs, iST7-1 and iST5-1, were identified for iST, the index RSD/RTD, in 2014 and 2015, respectively, and explained $30.9 \%$ and $27.4 \%$ of the phenotypic variation, respectively. One QTL, iMT7-1, was identified for iMT, the index RMD/RTD, in 2014 and explained 31.9\% of the phenotypic variation and had negative additive effects. Two QTLs, iMT2-1 and iMT2-2, were identified in 2015 and explained 36.3\% and $36.3 \%$, respectively of the phenotypic variation. Two QTLs for iSL, the index RSD/RL, were identified, iSL3-1 and iSL2-1, that explained $30.1 \%$ and $31.2 \%$ of the phenotypic variation in 2014 and 2015, respectively. Only one QTL, iML3-1, was identified for iML, the index RMD/RL, in 2014, and explained $16.5 \%$ of the phenotypic variation. Three QTLs, iTL2-1, iTL2-2, and iTL2-3, were identified for iTL, the index RTD/RL, in 2015 and explained $27.6,22.8$, and $12.3 \%$ of the phenotypic variation, respectively, but none of them were identified in 2014. A single QTL, iLR3-1, was identified for iLR, the index $\mathrm{LW} / \mathrm{RW}$, in 2014 that explained 15.7\% of the phenotypic variation, and two QTLs, iLR6-1 and $i L R 6-2$, were identified in 2015 that explained $16.0 \%$ and $18.7 \%$ of the phenotypic variation, respectively. Five QTLs (RL2-1, RSD2-2, DMC2-1, iSM2-1, and iSM2-2) were consistently detected in both years and were thus considered to be stable QTLs. Mostly, Af contributed positive additive effects for each QTL, while Ws contributed positive additive effects for QTLs related to MLL, LW, DMC, and iLR. 


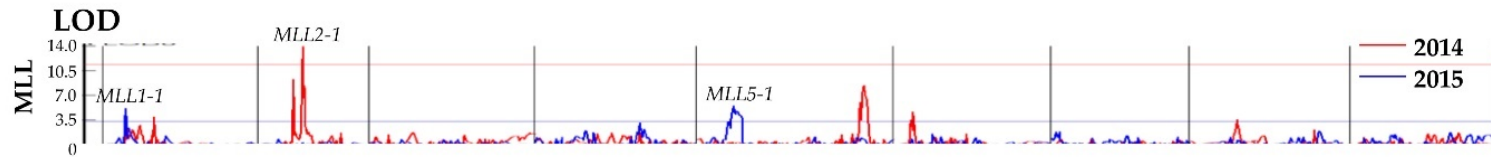
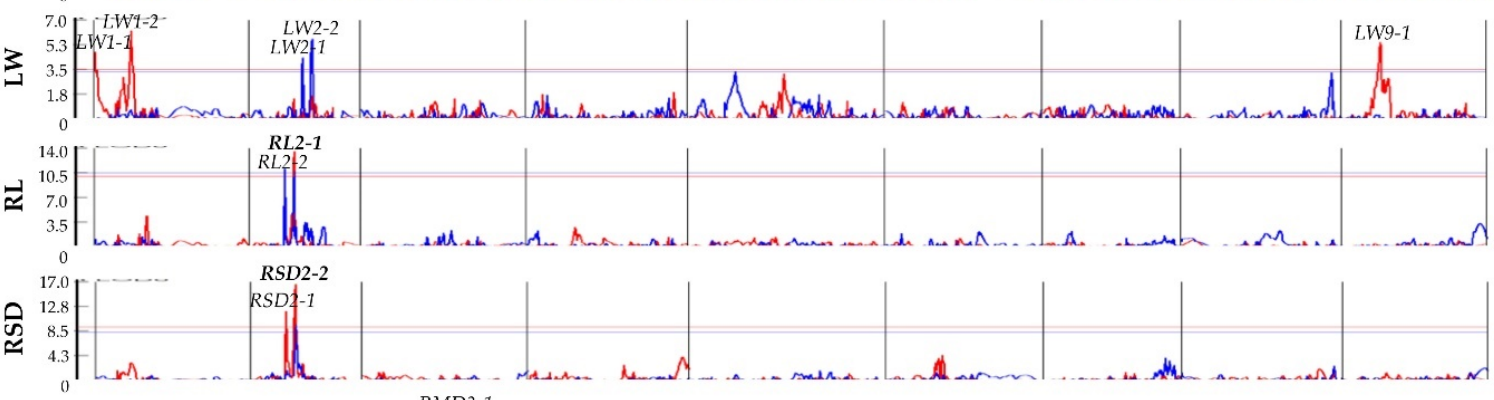

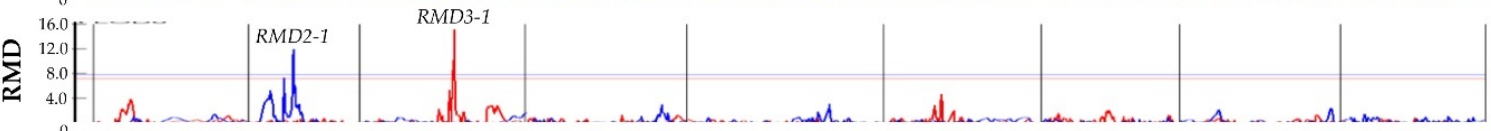

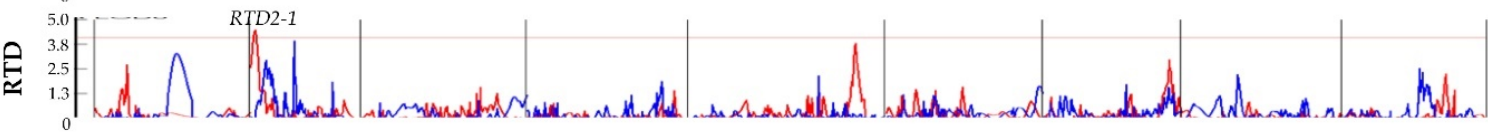

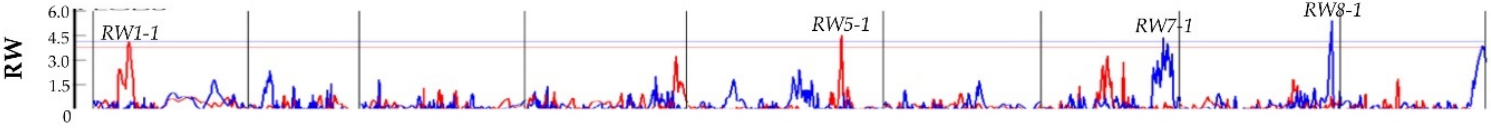

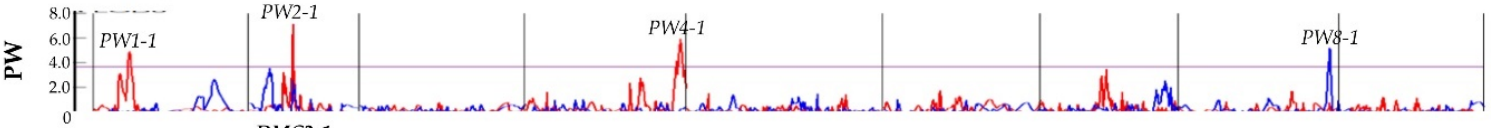
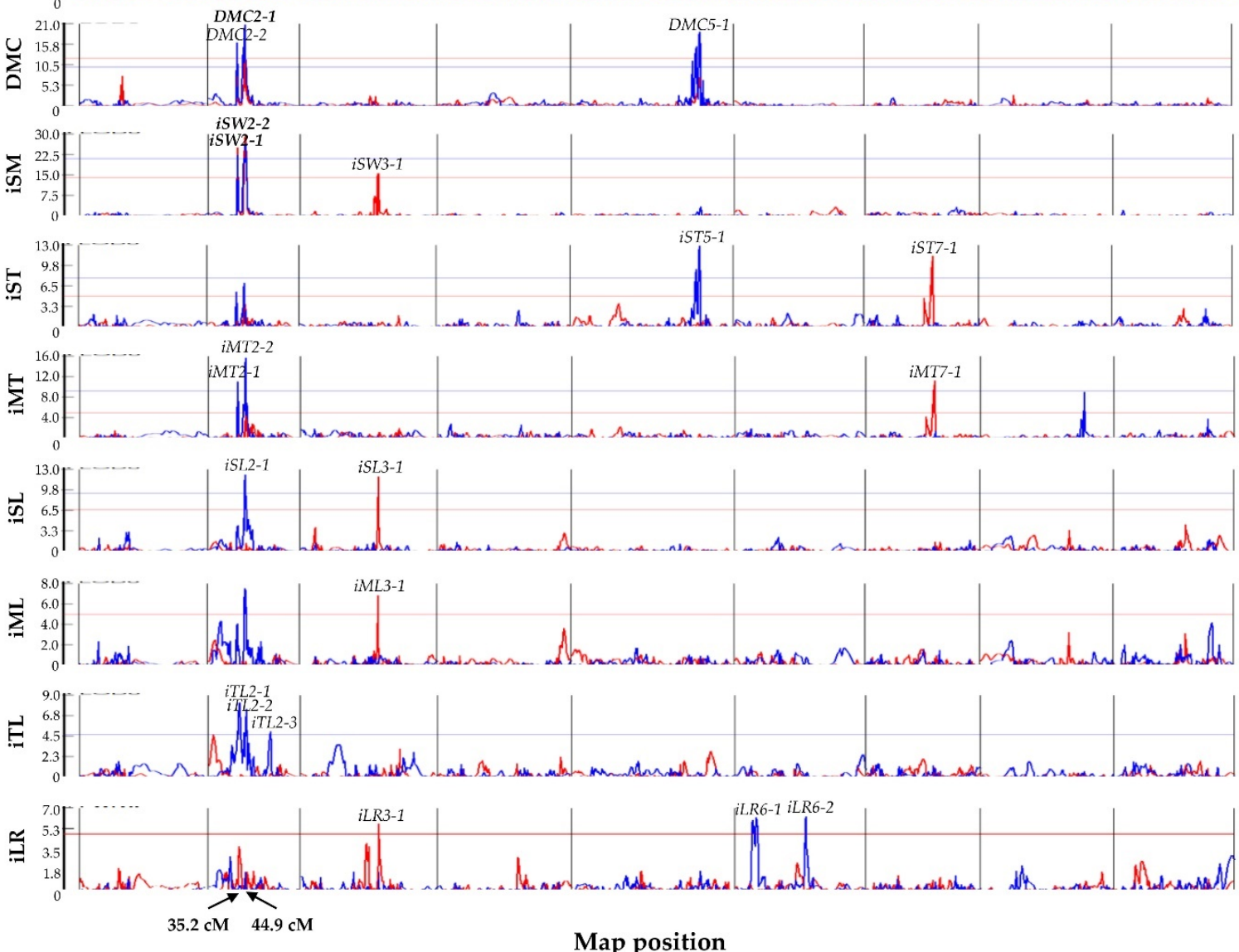

Figure 4. The QTLs of the morphological traits of the BIL population in 2014 and 2015. The curves indicate the genetic position ( $x$-axis) of bin markers against LOD score ( $y$-axis) of QTLs detected on 
nine chromosomes. The red and blue lines represent the LOD threshold in 2014 and 2015, respectively. Arrows indicate the position of clusters on chromosome 2. Cluster 1 was mapped at $35.2 \mathrm{~cm}$ including RL2-2, RSD2-1, DMC2-2, iSM2-1, and iMT2-1. Cluster 2 was mapped at $44.9 \mathrm{~cm}$ including MLL2-1, RL2-1, RSD2-2, RMD2-1, PW2-1, DMC2-1, iSM2-2, iMT2-2, and iSL2-1.

It was notable that RL2-2, RSD2-1, DMC2-2, iSM2-1, and iMT2-1 were clustered together in a $35.2 \mathrm{~cm}$ region of chromosome 2 and MLL2-1, RL2-1, RSD2-2, RMD2-1, PW2-1, DMC2-1, iSM2-2, iMT2-2, and iSL2-1 were clustered together in a $44.9 \mathrm{~cm}$ region of chromosome 2 (Table 3; Figure 4).

\section{Discussion}

Cultivated carrot (Daucus carota L. ssp. sativus) is the only subspecies with an edible root in the genus Daucus and has been suggested to be domesticated from the eastern wild species D. carota L. ssp. carota [4,41]. A significant signature of selection upon domestication showed that development of the large storage root was a transition from the wild species to the cultivated carrot [22]. After domestication and selection, the cultivated carrots differ in many morphological characters compared to the wild species, including increased size and variation in root shape, loss of lateral root branching, increased carotenoid and anthocyanin contents, and a biennial growth habit [42]. However, little is known about the effects of genome segments from the wild species during carrot domestication, especially for the mechanism of expansion of the storage root. MLL and RL in the $\mathrm{F}_{1}$ hybrids showed obvious heterosis, while root color, conical root shape, deep lateral root scars, and the annual growth habit of the $F_{1}$ were inherited from the Ws parent (Figure $\left.1 A, D\right)$. It was interesting that the $\mathrm{BC}_{1} \mathrm{~F}_{1}$ plants showed variation in root color, shape, and size, and only a few plants retained the annual growth habit or lateral roots from Ws (Figure 1B). The annual habit and/or presence of lateral roots may give these plants a reproductive advantage, but it was difficult for them to complete their reproductive cycles from autumn to winter. Thus, only 65 root stocks were left in the next year. The root color, shape, and size in the $\mathrm{BC}_{2} \mathrm{~S}_{2}$ population become more diverse, although none were purple in color (Figure 1C), a trait that can be stably transmitted to the BIL lines (Figure 1E). Some BIL root colors have not even been reported in carrot landraces, such as pale orange (Figure 1E). Most BIL lines appeared to have the biennial growth habit inherited from the Af parent, and only four lines retained the annual habit of Ws, which indicates that an annual growth habit may be a disadvantageous character for wild carrot species to survive, especially in the north of China. These results could explain why D. carota ssp. carota can complete the reproductive cycle as an annual but still retains the biennial growth habit and has thus spread widely in southern China [2]. Moreover, Chinese carrot landraces as the eastern type were more sensitive to premature bolting in early spring than the western varieties with orange roots [4,6], which suggests that these landraces have retained the annual growth habit from their progenitor to some degree. The annual growth habit is a disadvantageous character for commercial cultivars during the winter-spring period or spring cultivation; however, it is advantageous in that it enables these landraces to survive. This explains why nonadapted phenotypes may have had limited gene flow from the wild species, but a limited domestication bottleneck between wild and cultivated carrots [4,5]. During long-term domestication, the morphological traits were continuously selected in response to consumer needs by breeders, which resulted in local reductions in genetic variation of domestication genes in the cultivated populations compared to their wild counterparts [4,22].

Carrot root shape and size were the major commercial traits that distinguished the various types in the development of the orange carrot, which progressed due to selection since the 1600s [43]. In this study, nine morphological traits and seven indexes were used to analyze variation in the BIL population over two years. Average values for MLL, RL, DMC, iSM, and iLR appeared to be stable while the others showed significant differences between the two years (Figure 2). In particular, larger root diameters in 2015 (including 
RSD, RMD, and RTD) indicated that the roots were much thicker, and thus resulted in higher individual root weights based on the higher correlation coefficients between RW and RSD and between RW and RMD (Table 1).

QTL mapping provides more information to understand the genetic mechanisms for morphological traits. In this study, a total of 43 QTLs were detected using a high-density bin map for 16 morphological traits in carrot, while five out of them (RL2-1, RSD2-2, DMC2-1, iSM2-1, and iSM2-2) were stable in the two years. Most of the QTLs were only detected in one year. The same situation has been observed in other crops [19,44,45]. It indicates that the inheritance of morphological traits is affected by the interaction between genetic and environmental factors and is controlled by various genes under different environmental conditions. Thus, QTLs that were consistently identified in different environments can provide confirmation that these genetic loci can be reliably used to discover candidate genes in carrot. The four stable QTLs for root length and width (RL2-1, RSD2-2, iSM2-1, and iSM2-2) were located on the same chromosome as previously reported [22,23], and we can infer that the heredity of storage root shape and size in carrot is possibly controlled by candidate genes on chromosome 2. However, Macko-Podgórni et al. identified a $180 \mathrm{~kb}$ long region that was responsible for RSD on chromosome 1 [32]. These results indicated that the development of the storage root and expansion may be regulated by multiple genes. In addition, two clusters of QTLs were identified on chromosome 2. One was located in a 34.2-35.6 cm region compressing five QTLs related to RL, RSD, DMC, iSM, and iMT. The other was located in a $44.4-45.0 \mathrm{~cm}$ region compressing nine QTLs related to MLL, RL, RSD, RMD, PW, DMC, iSM, iMT, and iSL. These traits were partially correlated with each other at significant levels (Table 1), and represented different aspects of root shape, size, and biomass in carrot. For example, RL, RSD, RMD, iSM, iMT, and iSTL were the different components of root shape and size, while PW and DMC represented root biomass. Colocalization of QTLs for the correlated traits suggests the existence of pleiotropic linkage and similar regulating mechanisms. The phenomenon of genetic separation could effectively improve the utilization of genes and reduce gene loss resulting from genetic recombination $[44,46,47]$.

Cultivated carrot phenotypes are distinguished based on their root shapes and sizes. Several root morphological traits of interest to breeders, such as root length, root width, and biomass, were previously evaluated by means of labor-intensive measurement or image analysis [23]. In this study, a BIL population was used to examine the influence of genome introgression of the wild species on carrot storage root development. The root colors, shapes, and sizes in the BIL population became more diverse. Few lines retained an annual growth habit or lateral roots as wild parent, while most lines displayed an expanded storage root and biennial growth habit as cultivar parent. Five stable QTLs that contributed to four root traits were identified consistently in two years. The results presented here will provide more useful clues for the discovery of functional genes in future research and the development of molecular markers for selective breeding in carrot.

Supplementary Materials: The following supporting information can be downloaded at https: / /www.mdpi.com/article/10.3390/plants11030391/s1, Table S1: The statistics of sequence data, Table S2: The ratio of homozygous bins from Af on each chromosome, Table S3: The ratio of homozygous bins from Ws on each chromosome, Table S4: The genetic and genomic positions of bin markers.

Author Contributions: Data curation, C.O. and T.S.; formal analysis, C.O. and T.S.; investigation, T.S., X.L., M.L. and X.W.; project administration, C.L., H.R. and Z.Z.; resources, Z.Z.; supervision, F.Z.; writing-original draft, C.O. and T.S.; writing-review and editing, C.O. and F.Z. All authors have read and agreed to the published version of the manuscript.

Funding: This work was partially supported by the Agricultural Sciences and Technology Innovation Program (ASTIP), the China Agriculture Research System (CARS-23), the Central Public-interest Scientific Institution Basal Research Fund (IVF-BRF2020002).

Institutional Review Board Statement: Not applicable. 


\section{Informed Consent Statement: Not applicable.}

Data Availability Statement: All raw reads have been deposited in the Sequence Read Archive (SRA) under project PRJNA741874, accessions SRR14965956 and SRR14965957. Information about sequence data is available at https: / / www.ncbi.nlm.nih.gov / bioproject/?term=PRJNA741874 (1 January 2022).

Conflicts of Interest: The authors declare that they have no conflict of interest.

\section{References}

1. Rubatzky, V.E.; Simon, P.W.; Quiros, C.F. Carrots and Related Vegetable Umbelliferae; University Press: Cambridge, UK, 1999.

2. She, M.; Pu, F.; Pan, Z.; Mark, F.W.; John, F.M.C.; Ingrid, H.S.; Eugene, V.K.; Loy, R.P.; Michael, G.P. APIACEAE (UMBELLIFERAE). Flora China 2005, 14, 1-205.

3. IPGRI. Descriptors for Wild and Cultivated Carrots (Daucus carota L.); International Plant Genetic Resources Institute: Rome, Italy, 1998.

4. Iorizzo, M.; Senalik, D.; Ellison, S.; Grzebelus, D.; Cavagnaro, P.F.; Allender, C.; Bunet, J.; Spooner, D.M.; Deynze, A.V.; Simon, P.W. Genetic structure and domestication of carrot (Daucus carota subsp. sativus) (Apiaceae). Am. J. Bot. 2013, 100, 930-938. [CrossRef] [PubMed]

5. Iorizzo, M.; Ellison, S.; Senalik, D.; Zeng, P.; Satapoomin, P.; Huang, J.; Bowman, M.; Iovene, M.; Sanseverino, W.; Cavagnaro, P.; et al. A high-quality carrot genome assembly provides new insights into carotenoid accumulation and asterid genome evolution. Nat. Genet. 2016, 48, 657-666. [CrossRef]

6. Ma, Z.G.; Kong, X.P.; Liu, L.J.; Ou, C.G.; Sun, T.T.; Zhao, Z.W.; Miao, Z.J.; Rong, J.; Zhuang, F.Y. The unique origin of orange carrot cultivars in China. Euphytica 2016, 212, 37-49. [CrossRef]

7. Simon, P.W. Domestication, historical development, and modern breeding of carrot. Plant Breed. Rev. 2000, 19, 157-190.

8. Small, E. Numerical taxonomic analysis of Daucus carota complex. Can. J. Bot. 1978, 56, 248-276. [CrossRef]

9. Heywood, V.H. Relationship and evolution in the Daucus carota complex. Isr. J. Bot. 1983, 32, 51-65.

10. Rong, J.; Lanmers, Y.; Strasburg, J.L.; Schidlo, N.S.; Ariyurek, Y.; de Jong, T.J.; Klinkhamer, P.G.; Smulders, M.J.; Vrieling, K. New insights into domestication of carrot from root transcriptome analyses. BMC Genom. 2014, 15, 895. [CrossRef]

11. Grzebelus, D.; Baranski, R.; Spalik, K.; Allender, C.; Simon, P.W. Daucus. In Wild Crop Relatives: Genomic and Breeding Resources; Springer: Berlin/Heidelberg, Germany, 2011; pp. 91-113.

12. Li, Y.; Yang, L.; Pathak, M.; Li, D.; He, X.; Weng, Y. Fine genetic mapping of cp: A recessive gene for compact (dwarf) plant architecture in cucumber, Cucumis sativus L. Theor. Appl. Genet. 2011, 123, 973-983. [CrossRef]

13. Lv, H.; Fang, Z.; Yang, L.; Zhang, Y.; Wang, Q.; Liu, Y.; Zhuang, M.; Yang, Y.; Xie, B.; Liu, B.; et al. Mapping and analysis of a novel candidate Fusarium wilt resistance gene FOC1 in Brassica oleracea. BMC Genom. 2014, 15, 1094. [CrossRef]

14. Xie, W.; Feng, Q.; Yua, H.; Huang, X.; Zhao, Q.; Xinga, Y.; Yua, S.; Han, B.; Zhang, Q. Parent-independent genotyping for constructing an ultrahigh-density linkage map based on population sequencing. Proc. Natl. Acad. Sci. USA 2010, 107, 10578-10583. [CrossRef]

15. Qi, X.; Li, M.W.; Xie, M.; Liu, X.; Ni, M.; Shao, G.; Song, C.; Kay-Yuen, Y.A.; Tao, Y.; Wong, F.L.; et al. Identification of a novel salt tolerance gene in wild soybean by whole-genome sequencing. Nat. Commun. 2014, 5, 4340. [CrossRef]

16. Zhou, Z.; Zhang, C.; Zhou, Y.; Hao, Z.; Wang, Z.; Zeng, X.; Di, H.; Li, M.; Zhang, D.; Yong, H.; et al. Genetic dissection of maize plant architecture with an ultra-high density bin map based on recombinant inbred lines. BMC Genom. 2016, 17, 178. [CrossRef]

17. Huang, X.; Feng, Q.; Qian, Q.; Zhao, Q.; Wang, L.; Wang, A.; Guan, J.; Fan, D.; Weng, Q.; Huang, T.; et al. High-throughput genotyping by whole-genome resequencing. Genome Res. 2009, 19, 1068-1076. [CrossRef]

18. Nielsen, R.; Paul, J.S.; Albrechtsen, A.; Song, Y.S. Genotype and SNP calling from next-generation sequencing data. Nat. Rev. Genet. 2011, 12, 443-451. [CrossRef]

19. Han, K.; Jeong, H.J.; Yang, H.B.; Kang, S.M.; Kwon, J.K.; Kim, S.; Choi, D.; Kang, B.C. An ultra-high-density bin map facilitates high-throughput QTL mapping of horticultural traits in pepper(Capsicum annuum). DNA Res. 2016, 23, 81-91. [CrossRef]

20. Cavagnaro, P.F.; Iorizzo, M.; Yildiz, M.; Senalik, D.; Parsons, J.; Ellison, S.; Simon, P.W. A gene-derived SNP-based high resolution linkage map of carrot including the location of QTL conditioning root and leaf anthocyanin pigmentation. BMC Genom. 2014, 15, 1118. [CrossRef]

21. Ellison, S.; Senalik, D.; Bostan, H.; Iorizzo, M.; Simon, P.W. Fine mapping, transcriptome analysis, and marker development for $Y_{2}$, the gene that conditions $\beta$-carotene accumulation in carrot (Daucus carota L.). G3 2017, 7, 2665-2675. [CrossRef]

22. Macko-Podgórni, A.; Machaj, G.; Stelmach, K.; Senalik, D.; Grzebelus, E.; Iorizzo, M.; Simon, P.W.; Grzebelus, D. Characterization of a genomic region under selection in cultivated carrot (Daucus carota subsp. sativus) reveals a candidate domestication gene. Front. Plant Sci. 2017, 8, 12.

23. Turner, S.D.; Ellison, S.L.; Senalik, D.A.; Simon, P.W.; Spalding, E.P.; Miller, N.D. An automated image analysis pipeline enables genetic studies of shoot and root morphology in carrot (Daucus carota L.). Front. Plant Sci. 2018, 9, 1703. [CrossRef]

24. Bannoud, F.; Carvajal, S.; Ellison, S.; Senalik, D.; Gomez Talquenca, S.; Iorizzo, M.; Simon, P.W.; Cavagnaro, P.F. Genetic and transcription profile analysis of tissue-specific anthocyanin pigmentation in carrot root phloem. Genes 2021, 12, 1464. [CrossRef] [PubMed] 
25. Ou, C.G.; Zhao, Z.W.; Hu, H.; Pei, H.X.; Zhuang, F.Y. Genetic and Heterosis analysis for root width and length in carrot (Daucus carota L.). Acta Hortic. Sin. 2009, 36, 115-120.

26. Rosenfeld, H.J.; Dalen, K.S.; Haffner, K. The growth and development of carrot roots. Gartenbauwissenschaft 2002, 67, 11-16.

27. Thompson, R. Some factors affecting carrot root shape and size. Euphytica 1969, 18, 277-285. [CrossRef]

28. Thomas, T.H. Effect of root restriction and growth regulator treatments on the growth of carrot (Daucus carota L.) seedlings. Plant Growth Regul. 1993, 13, 95-101. [CrossRef]

29. Wu, X.J.; Wang, G.L.; Song, X.; Xu, Z.S.; Wang, F.; Xiong, A.S. Regulation of auxin accumulation and perception at different developmental stages in carrot. Plant Growth Regul. 2016, 80, 243-251. [CrossRef]

30. Wang, G.L.; Que, F.; Xu, Z.S.; Wang, F.; Xiong, A.S. Exogenous gibberellin altered morphology, anatomic and transcriptional regulatory networks of hormones in carrot root and shoot. BMC Plant Biol. 2015, 15, 290. [CrossRef]

31. Wang, G.L.; Que, F.; Xu, Z.S.; Wang, F.; Xiong, A.S. Exogenous gibberellin enhances secondary xylem development and lignification in carrot taproot. Protoplasma 2017, 254, 839-848. [CrossRef]

32. Macko-Podgórni, A.; Stelmach, K.; Kwolek, K.; Machaj, G.; Ellison, S.; Senalik, D.A.; Simon, P.W.; Grzebelus, D. Mining for candidate genes controlling secondary growth of the carrot storage root. Int. J. Mol. Sci. 2020, 21, 4263. [CrossRef]

33. Jeuken, M.J.W.; Pelgrom, K.; Stam, P.; Lindhout, P. Efficient QTL detection for nonhost resistance in wild lettuce: Backcross inbred lines versus $\mathrm{F}_{2}$ population. Theor. Appl. Genet. 2008, 116, 845-857. [CrossRef]

34. Ou, C.G.; Mao, J.H.; Liu, L.J.; Li, C.J.; Ren, H.F.; Zhao, Z.W.; Zhuang, F.Y. Characterizing genes associated with flowering time in carrot (Daucus carota L.) using transcriptome analysis. Plant Biol. 2017, 19, 286-297. [CrossRef]

35. Liu, L.J.; Ou, C.G.; Chen, S.M.; Shen, Q.; Liu, B.; Li, M.; Zhao, Z.W.; Kong, X.P.; Yan, X.P.; Zhuang, F.Y. The response of COL and FT homologues to photoperiodic regulation in carrot (Daucus carota L.). Sci. Rep. 2020, 10, 9984. [CrossRef]

36. Briard, M.; Clerc, V.L.; Grzebelus, D.; Senalik, D.; Simon, P.W. Modified protocols for rapid carrot genomic DNA extraction and AFLP $^{\mathrm{TM}}$ analysis using silver stain or radioisotopes. Plant Mol. Biol. Rep. 2000, 18, 235-241. [CrossRef]

37. Li, H.; Durbin, R. Fast and accurate short read alignment with Burrows-Wheeler transform. Bioinformatics 2009, 25, 1754-1760 [CrossRef]

38. DePristo, M.A.; Banks, E.; Poplin, R.; Garimella, K.V.; Maguire, J.R.; Hartl, C.; Philippakis, A.A.; Angel, G.D.; Rivas, M.A.; Hanna, M.; et al. A framework for variation discovery and genotyping using next-generation DNA sequencing data. Nat. Genet. 2011, 43, 491-498. [CrossRef]

39. Van Ooijen, J.W. JoinMap 4.0: Software for the Calculation of Genetic Linkage Maps in Experimental Populations; Kyazma B.V.: Wageningen, The Netherlands, 2006.

40. Wang, S. Windows QTL Cartographer 2.5; Department of Statistics, North Carolina State University: Raleigh, NC, USA, 2011. Available online: http:/ / statgen.ncsu.edu/qtlcart/WQTLCart.htm (accessed on 1 January 2022).

41. Que, F.; Hou, X.L.; Wang, G.L.; Xu, Z.S.; Tan, G.F.; Li, T.; Wang, Y.H.; Khadr, A.; Xiong, A.S. Advances in research on the carrot, an important root vegetable in the Apiaceae family. Hortic. Res. 2019, 6, 69. [CrossRef]

42. Ellison, S. Carrot domestication. In The Carrot Genome; Springer: Berlin/Heidelberg, Germany, $2019 ;$ pp. 77-91.

43. Simon, P.W.; Freeman, R.E.; Vieira, J.V.; Boiteux, L.S.; Briard, M.; Nothnagel, T.; Michalik, B.; Kwon, Y.S. "Carrot”. In Vegetables II: Fabaceae, Liliaceae, Solanaceae, and Umbelliferae; Prohens, J., Nuez, F., Eds.; Springer: New York, NY, USA, 2008 ; pp. $327-357$.

44. Zou, G.; Zhai, G.; Feng, Q.; Yan, S.; Wang, A.; Zhao, Q.; Shao, J.; Zhang, Z.; Zou, J.; Han, B.; et al. Identification of QTLs for eight agronomically important traits using an ultra-high-density map based on SNPs generated from high-throughput sequencing in sorghum under contrasting photoperiods. J. Exp. Bot. 2012, 63, 5451-5462. [CrossRef]

45. Gao, Z.; Zhang, H.; Cao, C.; Han, J.; Li, H.; Ren, Z. QTL Mapping for cucumber fruit size and shape with populations from long and round fruited inbred lines. Hortic. Plant J. 2020, 6, 132-144. [CrossRef]

46. Santos, C.A.F.; Simon, P.W. QTL analyses reveal clustered loci for accumulation of major provitamin a carotenes and lycopene in carrot roots. Mol. Gen. Genom. 2002, 268, 122-129. [CrossRef]

47. Liu, D.; Zhang, J.; Liu, X.; Wang, W.; Liu, D.; Teng, Z.; Fang, X.; Tan, Z.; Tang, S.; Yang, J.; et al. Fine mapping and RNA-Seq unravels candidate genes for a major QTL controlling multiple fiber quality traits at the $\mathrm{T}_{1}$ region in upland cotton. BMC Genom. 2016, 17, 295. [CrossRef] 